\title{
Implementação do Plano Municipal de Gestão Integrada de Resíduos Sólidos no Município de Natal (Rn): O Papel dos Atores
}

Mendes Teixeira, Jeanne Christine; Duarte de Araújo, Maria Arlete

Implementação do Plano Municipal de Gestão Integrada de Resíduos Sólidos no Município de Natal (Rn): O

Papel dos Atores

Administração Pública e Gestão Social, vol. 12, núm. 4, 2020

Universidade Federal de Viçosa, Brasil

Disponible en: http://www.redalyc.org/articulo.oa?id=351564289013

Esta obra está bajo una Licencia Creative Commons Atribución-NoComercial-SinDerivar 3.0 Internacional. 


\title{
Implementação do Plano Municipal de Gestão Integrada de Resíduos Sólidos no Município de Natal (Rn): O Papel dos Atores
}

\author{
Implementation of the Municipal plan for Integrated Management of Solid Waste in the Municipality of Natal \\ $(\mathrm{Rn})$ : The Role of the Actors \\ Implementación del plan Municipal de Gestión Integrada de Residuos Sólidos en el Municipio de Natal (Rn): El \\ Rol de los Actores
}

Jeanne Christine Mendes Teixeira

Universidade Federal do Rio Grande do Norte - UFRN,

Redalyc: http://www.redalyc.org/articulo.oa?

Brasil

jeanneteixeira@yahoo.com.br

Maria Arlete Duarte de Araújo

Universidade Federal do rio Grande do Norte - UFRN,

Brasil

Mariaarlete1956@gmail.com id $=351564289013$

Recepción: 31 Diciembre 2018

Aprobación: 10 Febrero 2020

Publicación: 01 Octubre 2020

\section{Resumo:}

O artigo analisa a dinâmica dos atores envolvidos na implementação do Plano Municipal de Gestão Integrada de Resíduos Sólidos (PMGIRS) no município de Natal, no Rio Grande do Norte. A partir de pesquisa bibliográfica e entrevista constatou-se que o envolvimento de múltiplos atores gerou uma profusão de ideias e ações que resultaram em duas dinâmicas: A dinâmica de implementação do PMGIRS decorrente de ações pró-ambientais realizadas pelos grandes geradores de resíduos e a dinâmica de limitação que opera em função do desconhecimento dos instrumentos legais e suas diretrizes por parte de atores envolvidos na execução de ações do PMGIRS. Essas duas dinâmicas apresentam dificuldades à execução do PMGIRS em função da estrutura de governança existente que reforça o desconhecimento, por parte dos atores, do conteúdo da Política Nacional de Resíduos Sólidos (PNRS) e das ações que compõem o PMGIRS Natal.

Palavras-Chave: s: Resíduos Sólidos, Plano Municipal de Gestão Integrada de Resíduos Sólidos (PMGIRS), Política Pública.

\section{Abstract:}

The article analyzes the dynamics of the actors involved in the implementation of PMGIRS (Plan for Integrated Management of Solid Waste) in the municipality of Natal, in the Northeast region of Brazil. With a bibliographical research and interview it was verified that the involvement of multiple actors generated a profusion of ideas and actions that resulted in two dynamics: The dynamics of implementation of the PMGIRS resulting from the accomplishment of pro-environmental actions carried out by large waste generators and the dynamics of limiting that operates due to the lack of knowledge of the legal instruments and their guidelines by actors involved in the execution of PMGIRS actions. These two dynamics present difficulties in the execution of the PMGIRS due to the existing governance structure that reinforces the actors' lack of knowledge of the content of the PNRS (National Solid Waste Policy) and of the actions that make up the PMGIRS in Natal.

KEYWORDS: Solid Waste, Municipal Plan for Integrated Solid Waste Management (PMGIRS), Public Policy.

\section{Resumen:}

El artículo analiza la dinámica de los actores involucrados en la implementación del Plan Municipal para la Gestión Integrada de Residuos Sólidos (PMGIRS) en el municipio de Natal, capital del estado de Rio Grande do Norte, en Brasil. A partir de investigación bibliográfica y entrevista se constató que la participación de múltiples actores generó una profusión de ideas y acciones que resultaron en dos dinámicas: La dinámica de implementar el PMGIRS resultante de acciones pro-ambientales realizadas por los grandes generadores de residuos y la dinámica de limitar que opera en función del desconocimiento de los instrumentos legales y sus directrices por parte de actores involucrados en la ejecución de acciones del PMGIRS. Estas dos dinámicas presentan dificultades 
para la ejecución del PMGIRS en función de la estructura de gobernanza existente que refuerza el desconocimiento por parte de los actores del contenido de la Política Nacional de Residuos Sólidos (PNRS) y de las acciones que componen el PMGIRS en Natal. Palabras Clave: Residuos Sólidos, Plan municipal para la gestión integrada de residuos sólidos (PMGIRS), Política Publica.

\section{INTRODUÇão}

O impacto decorrente do modo de desenvolvimento econômico atual exerce influência sobre os recursos naturais acarretando problemas de efeitos distintos dependendo do espaço e da localização em que ocorrem (Sen, 1999; Simão, 2008). Boa parte dos problemas ambientais - como poluição do ar, contaminação de água potável e do lençol freático - tende a atravessar fronteiras em nível global ou local e gera demandas econômicas, sociais e políticas em seu processo de solução.

Os problemas relacionados ao meio ambiente levaram a uma reflexão em torno das políticas ambientais em termos globais, impulsionando o surgimento do conceito de Desenvolvimento Sustentável (DS) como uma alternativa para a utilização dos recursos naturais de forma correta.

No Brasil, as discussões em torno da Política Ambiental Brasileira envolveram os três entes federativos União, estados e municípios -, além do setor produtivo e da sociedade em geral. Considerando as políticas públicas estabelecidas pela Constituição Federal de 1988, destaque deve ser dado à Política Nacional de Resíduos Sólidos (PNRS) aprovada em 02 de agosto de 2010, como Lei n. 12.305/10 e regulamentada em 23 de dezembro de 2010 pelo Decreto n. 7.404/10, que propõe o tratamento dos resíduos sólidos, bem como a disposição adequada dos rejeitos, o estabelecimento pelos estados e municípios de planos para a gestão de resíduos sólidos, a implantação da logística reversa e de estrutura que auxilie a inclusão social de catadores de materiais recicláveis (Lei n. 12.305, 2010).

O Plano de Gestão Integrada de Resíduos Sólidos do Município de Natal (PMGIRS/Natal) foi aprovado pelo Decreto n. 9.721, de 11 de junho de 2012, e em seu art. $2^{\circ}$ estabelece que a Companhia de Serviços Urbanos de Natal (URBANA) é responsável pelo cumprimento do Plano no exercício direto de suas funções e pela fiscalização de seu cumprimento pelas empresas que prestam serviços de limpeza e coleta no âmbito do município, nos termos da Lei 4.748/96[1], bem como pelo cumprimento do plano, no que couber, segundo o art. $3^{\circ}$, à Secretaria Municipal de Serviços Urbanos (SEMSUR) e à Secretaria Municipal de Meio Ambiente e Urbanismo (SEMURB).

O PMGIRS foi precedido por um diagnóstico da situação dos resíduos sólidos, elaborado em 2011, e trouxe um conjunto de responsabilidades aos gestores municipais, entre as quais: A necessidade de realização de diagnóstico da situação dos resíduos sólidos; a identificação de áreas disponíveis para o estabelecimento de futuros aterros sanitários; a realização de programas e ações de capacitação técnica, direcionados para a operacionalização do PMGIRS/Natal; a criação de programas e ações de educação ambiental, relacionados ao descarte consciente dos resíduos; o estabelecimento de metas para a redução de rejeitos encaminhados para disposição final, bem como a necessidade de mudanças estruturais em relação ao gerenciamento dos resíduos sólidos urbanos do município de Natal.

Atualmente, o município de Natal possui 877.640 habitantes e é responsável pela produção de 734 toneladas por dia de resíduos de coleta domiciliar, 286 de entulho e resíduo de construção civil, 34 de poda de árvores, além de 8 toneladas por dia de coleta seletiva, totalizando 1062 toneladas por dia, conforme dados da URBANA (2017).

As ações contidas no Plano Municipal de Gestão Integrada de Resíduos Sólidos do Município de Natal, por articularem diferentes atores e dimensões sociais, econômicas e ambientais, influenciam as interações políticas em torno da tomada de decisão tornando dinâmica a execução de suas ações. Sobre esse aspecto, Silveira e Clementino (2017, p.16) comentam: "Sempre existirão múltiplos atores envolvidos na formulação de uma política, seja direta ou indiretamente. Tais atores buscarão influenciar esse processo como forma de confirmar seus interesses no tocante à política discutida". O município de Natal, ao pôr em prática a 
execução do Plano Municipal de Gestão Integrada de Resíduos Sólidos (PMGIRS), conforme exigido pela lei, trouxe novas responsabilidades aos gestores municipais, como a necessidade de realização de diagnóstico da situação dos resíduos sólidos, a identificação de áreas disponíveis para o estabelecimento de futuros aterros sanitários, a realização de programas e ações de capacitação técnica direcionados para a operacionalização do PMGIRS/Natal e a criação de programas e ações de educação ambiental relacionados ao descarte consciente dos resíduos. A colocação em prática dessas novas responsabilidades vem acompanhada de alguns obstáculos, tais como a necessidade de pessoal qualificado para desenvolver ações contínuas de educação ambiental, a definição em termos de plano diretor da cidade de área para futuro aterro sanitário e a contratação de pessoal capacitado para operacionalizar o PMGIRS. De acordo com Waldman (2013 como citado em Silveira \& Clementino, 2017, p. 13):

A avaliação [da PNRS] ganha contornos de maior gravidade quando se sabe que mesmo os planos elaborados apresentam muitas falhas técnicas e lacunas, como ausência de metas e de custos de implantação dos programas, transformando esses documentos em verdadeiros pronunciamentos retóricos.

A elaboração dos Planos Municipais de Gestão integrada tem sido um dos obstáculos mais frequentes quando da implementação da PNRS. Além disso, "outro aspecto que não pode ser esquecido é o viés político que permeia as decisões a serem tomadas para que a PNRS seja, efetivamente, posta em prática. A formulação de uma política envolve múltiplos interesses" (Deubel, 2012 como citado em Silveira \& Clementino, 2017, p.17). A participação dos atores envolvidos num contexto político acaba por gerar ações, ou a falta de ações, comprometendo a implementação de uma política.

Em conformidade com o pensamento de Lascoumes e Le Galès (2012, p. 201) nota-se que "os instrumentos de ação pública são portadores de valores, alimentam-se de uma interpretação do social e de concepções precisas do modo de regulação esperado”. Desse modo, os planos contidos numa política são instrumentos que incorporam valores e são capazes de organizar o comportamento coletivo para a execução da ação pública.

Assim, o foco deste artigo recai sobre a forma como se deu a apropriação de um instrumento de ação pública (PMGIRS) pelos diversos atores envolvidos com a sua implementação e as transformações ocorridas na gestão de resíduos sólidos como consequência das articulações processadas durante a implementação do PMGIRS em nível local.

Para dar conta deste objetivo, além desta introdução, este artigo se estrutura da seguinte forma: Na seção seguinte, analisa as políticas públicas, do ponto de vista da implementação da ação do Estado, conforme a perspectiva da abordagem sociológica da ação pública denominada de Pentágono das Políticas Públicas (PPP) de Lascoumes e Le Galès (2012), com destaque para as relações entre os múltiplos atores individuais e coletivos; na terceira seção, apresenta o percurso metodológico; na quarta, analisa a dinâmica entre os atores e as articulações que se processaram na implementação do PMGIRS e, por último, apresenta um retrato das condições atuais sobre as dificuldades e avanços obtidos com a implementação do PMGIRS.

\section{A Política Como Ação Pública e a Implementação de Política Pública}

Uma política pública busca a resolução de conflitos coletivos de forma ordenada. Desse modo, as políticas públicas são introduzidas pelos governos como uma ferramenta para auxiliar na organização da ordem social. Seguindo esta linha de pensamento, Rodrigues (2010, p. 13) afirma que a política é entendida como "um conjunto de procedimentos que expressa relações de poder e que se orienta à resolução de conflitos no que se refere aos bens públicos". Seguindo a perspectiva de ordenamento social, Lascoumes e Le Galès (2012, p. 31), ao definirem políticas públicas, afirmam que estas "são ações coletivas que participam da criação de determinada ordem social e política, da direção da sociedade, da regulação de suas tensões, da integração dos grupos e da resolução de conflitos". Todas as fases do ciclo de políticas públicas fornecem importantes 
elementos de análise. Entre elas, a implementação de uma política tem sido uma das fases mais estudadas. De acordo com Van Meter e Van Horn (1975, p. 447), “a implementação de políticas públicas abrange as ações realizadas por indivíduos públicos ou privados, ou grupos que são direcionados para o alcance de objetivos estabelecidos numa decisão política". Em uma perspectiva próxima à de Van meter e Van Horn (1975), Sabatier e Mazmanian (1983, pp. 20-21) afirmam que, "a implementação de políticas é a realização de uma decisão política, geralmente incorporada em uma lei, mas que também pode ter a forma de importantes decisões administrativas ou decisão judicial".

De um ponto de vista mais contemporâneo, Oliveira (2006, pp. 277-278) destaca que "o estudo de implementação requer um entendimento de sua complexidade e de sua interação com o processo de planejamento". Para o autor, o resultado de um processo de planejamento, incluindo sua implementação, depende de uma cadeia complexa de interações recíprocas para que obtenha o resultado esperado e muitas vezes essa cadeia não pode ser prevista ou controlada (Oliveira, 2006).

De modo geral, encontramos tanto autores que analisam a política pública de modo estado-centrada como autores que, ao analisarem a implementação, consideram a pluralidade de atores que permeiam o ambiente político a partir da complexidade de suas relações. Neste sentido, analisar uma política a partir da fase de implementação, segundo Lascoumes e Le Galès (2012, p. 66), “[...] significa interessar-se pela forma com que um programa público é apropriado e não apenas pela forma como ele foi concebido e estruturado". Ou seja, consiste em olhar para uma política pública sob a perspectiva real de como se deu a ação pública e suas consequências.

Um aspecto relevante ao se estudar uma política pública está em compreender a ação pública como formada por instrumentos, que são utilizados como estruturas organizadoras e portadores de valor, sendo capazes de produzir representações sobre o público ao qual se direciona. Sobre instrumentos de ação pública, Lascoumes e Le Galès (2012, p. 21) afirmam que estes constituem "um dispositivo ao mesmo tempo técnico e social que organiza relações sociais específicas entre o poder público e seus destinatários em função das representações e das significações das quais é portador". A abordagem da ação pública por meio de seus instrumentos permite visualizar os efeitos sociais gerados.

O processo de instrumentação realça a atuação dos atores em relação aos conflitos, interesses e, se for o caso, coalizões. É nessa etapa do processo que os atores mais produtivos conseguem a aprovação de determinados instrumentos em detrimento de outros que, à medida que são postos em prática, geram determinados efeitos.

Essa perspectiva está em conformidade com a perspectiva da abordagem sociológica "dada a ênfase aos atores públicos e privados, às representações, às instituições, processos e resultados, as relações de poder, bem como ao papel do Estado, uma vez que a política pública não se resume somente à ação deste" (Pinto, 2014, p. 27), e com as análises de modelo de implementação bottom-up, cuja regulação se dá por meio da interação entre os múltiplos atores evidenciando uma atuação não linear do Estado.

Como ferramenta de análise da ação pública, os autores Lascoumes e Le Galès (2012) propõem um modelo chamado de Pentágono das Políticas Públicas (PPP), formado por cinco elementos, a saber: Atores, instituições, processos, representações e resultados. Tais elementos encontram-se descritos no Quadro 1. 
Quadro 1 - Descrição dos elementos que compõem o Pentágono das Políticas Públicas

\begin{tabular}{|l|l|}
\hline Elementos & Descrição \\
\hline Atores & $\begin{array}{l}\text { Os atores podem ser individuais ou coletivos; são } \\
\text { dotados de recursos, possuem certa autonomia, } \\
\text { estratégias e capacidade de fazer escolhas. São } \\
\text { mais ou menos guiados por interesses materiais } \\
\text { ou simbólicos. }\end{array}$ \\
\hline Representações & $\begin{array}{l}\text { São espaços cognitivos e normativos que dão } \\
\text { sentido às ações, as condicionam e as refletem. }\end{array}$ \\
\hline Instituições & $\begin{array}{l}\text { São normas, regras, rotinas, procedimentos que } \\
\text { governam as interações. }\end{array}$ \\
\hline Processos & $\begin{array}{l}\text { São as formas de interação e sua recomposição no } \\
\text { tempo. Justificam as múltiplas atividades e } \\
\text { mobilização dos atores individuais e coletivos. }\end{array}$ \\
\hline Resultados & São as consequências, os efeitos da ação pública. \\
\hline
\end{tabular}

Fonte: Adaptado de Lascoumes e Le Galés (2012, p. 46).

Ao aplicar o modelo do Pentágono das Políticas Públicas para o estudo da ação pública, a análise de cada um de seus elementos torna-se fundamental para um completo entendimento da aplicação do modelo.

Os atores são indivíduos envolvidos no contexto político que desenvolvem ações passíveis de influenciar a implementação de uma política. Eles possuem um papel dinâmico no cenário político, visto que são responsáveis por alocação de recursos, resolução de conflitos e construção de coalizões.

O papel dos atores no cenário político é um tema consideravelmente abordado. Na concepção de Niederle e Grisa (2013, p. 99), analisar o papel dos atores consiste em: "Identificar as lógicas da ação coletiva, e as estratégias desenvolvidas em função de custos e benefícios esperados da ação, assim como as consequências das antecipações feitas pelos indivíduos ou pelas organizações envolvidas na ação pública".

As imagens criadas pelos atores são compreendidas como normas que orientam e dão sentido às suas ações. De modo geral, as representações referem-se às crenças, aos valores e às ideias compartilhadas que constituem a base das práticas sociais, em que os elementos simbólicos e argumentativos exercem influência importante na determinação das políticas. Na concepção de Lascoumes e Le Galès (2012, p. 115), as representações "tomam como ponto de partida a generalização de certas formas de discursos argumentativos que orientam e legitimam o posicionamento dos principais atores e das arbitragens públicas”. São os elementos cognitivos (crenças, valores e ideias) que determinam as práticas mais apropriadas para a execução dos objetivos de uma política.

Por sua vez, as instituições podem ser descritas como normas, instrumentos e procedimentos que regulam o comportamento dos atores, sendo vistas como estruturas não portadoras de neutralidade, podendo favorecer atores e interesses coletivos. Nesse sentido, considerar os instrumentos de ação pública como um tipo particular de instituição que pode ser elaborado de acordo com a necessidade política é uma forma particular de abordagem da análise da política como um meio de viabilizar a estabilidade coletiva a partir de uma perspectiva local.

A etapa referente aos processos está associada à tomada de decisão que pode ser abordada a partir da fase de formulação e da fase de legitimação. A formulação "designa, inicialmente, a atividade de escolha das respostas dada a uma questão política. Por sua vez, a legitimação se refere aos mecanismos de escolha que vão tornar aceitáveis as escolhas realizadas pelos governos" (Muller \& Surel, 2002, p. 102). De modo geral, a etapa de processos constitui um fluxo contínuo de decisões decorrentes do arranjo da mobilização de atores individuais e coletivos que devem levar em consideração elementos como as regras de organização, as estratégias de poder e as rotinas burocráticas que envolvem o contexto político.

Por sua vez, os resultados podem ser descritos como os avanços ou inércias alcançadas no decorrer da implementação de uma política. Eles "consistem em construir a lógica da mudança relacionada às 
características da própria decisão numa sequência que pode sintetizar o conteúdo e as evoluções da ação pública" (Muller \& Surel, 2002, p. 122).

Os resultados envolvem as consequências, as limitações legais, adaptações estruturais, as transformações políticas, em função das relações entre os atores e as políticas envolvidas, de modo que as escolhas realizadas pelos atores vão estruturar os resultados obtidos.

A análise da dinâmica entre os elementos do modelo do PPP, como base para a análise de implementação de políticas públicas, é capaz de fornecer resultados significativos sobre as dinâmicas que ocorrem em um processo de execução de uma política, enfatizando as transformações ou as adaptações ocorridas durante a execução, diferentemente das análises de implementação efetuadas em função do sucesso ou do fracasso de uma política.

A seguir, o percurso metodológico utilizado com destaque para o papel dos atores na implementação do PMGIRS. Os outros elementos do modelo do PPP deixam de ser contemplados pelas limitaçóes de formato do artigo, mas são igualmente importantes e estão imbricados com os papéis dos atores.

\section{Percurso Metodológico}

A pesquisa classifica-se como exploratória e descritiva. Como estratégia de investigação fez-se uso do método de estudo de caso. Caracteriza-se como uma pesquisa de natureza qualitativa que busca compreender as ações de indivíduos, grupos ou organizações em seu contexto social, realizando interpretações segundo a perspectiva dos participantes da situação enfocada.

São sujeitos da pesquisa os seguintes atores: A Diretora de Planejamento e Gestão Ambiental do órgão público responsável pela execução do PMGIRS/Natal (EOPM1); a Secretária Adjunta de Informação, Planejamento Urbanístico e Ambiental (EOPM4); a Diretora do Departamento de Ação Socioambiental (EOPM3) e o Chefe do setor de Educação Ambiental (EOPM2) do órgão público responsável pela implementação de ações de educação ambiental do município de Natal. Para ampliar os dados coletados foram entrevistados um representante da Cooperativa de Catadores (ECT), a Diretora da Divisão de Meio Ambiente de uma Instituição de Ensino Superior (EIES), a Supervisora Geral de um Supermercado Varejista (ESV) e o gerente do setor de resíduos sólidos de um shopping center (ESC).

A coleta dos dados deu-se em junho de 2017 e a escolha dos atores deu-se por acessibilidade e pelo envolvimento de cada um com a realização de ações ligadas à gestão de resíduos sólidos urbanos, conforme estabelecido no PMGIRS/Natal (2012).

A coleta de dados utilizou-se de pesquisa bibliográfica, entrevista semiestruturada e pesquisa documental referente aos diversos planos sobre resíduos sólidos existentes. Foram consultadas fontes secundárias de dados, como bancos de teses e periódicos (Coordenação de Aperfeiçoamento de Pessoal de Nível Superior [CAPES], Universidade de São Paulo [USP], Biblioteca Digital Brasileira de Teses e Dissertações [BDTD], Scientific Periodics Electronic Library [SPELL], Scopus) por meio de pesquisa on-line, a partir da utilização de palavras-chave (implementação, ação pública, resíduos sólidos urbanos, política pública). As entrevistas procuraram identificar o grau de conhecimento dos atores sobre a PNRS, dificuldades na implementação do PMGIRS, papel dos atores envolvidos - catadores, cooperativas, grandes geradores e poder público -, ações para a redução dos resíduos, coleta seletiva, programas de educação ambiental, entre outros aspectos.

Para efeito deste trabalho será dada maior ênfase ao papel dos atores, suas interações e resultados em relação à implementação do Plano Municipal de Gestão Integrada de Resíduos Sólidos do Município de Natal (PMGIRS/Natal), pelas limitações de escopo e forma deste artigo. Deixam de merecer maior atenção as categorias de representações e instituições que sustentam o modelo do PPP. Reconhece-se, no entanto, que essas categorias constituem pano de fundo explicativo sobre a forma como os atores agem. 
Quanto à fase de interpretação de dados, buscou-se, a partir das falas dos sujeitos e da análise documental, gerar convergências, divergências ou comparações entre os dados, de modo a permitir a compreensão da atuação e interação dos atores na implementação da PMGIRS/Natal.

\section{Dinâmica da Implementação do PMGIR/Natal: O Papel dos Atores}

Os atores, tanto públicos quanto privados, assumem um papel significativo na implementação das políticas públicas, uma vez que são capazes de mobilizar recursos e estabelecer articulações entre outros atores, de modo a pôr em prática as metas, os programas e os planos estabelecidos. A este respeito, Lascoumes e Le Galès (2012, p. 18) afirmam que "o ator público e o ator privado devem ser capazes de desenvolverem estratégias de ação que, efetivamente, tenham repercussões palpáveis sobre o desenrolar de determinada ação pública a ponto de modificá-la, aprimorar ou ampliar o seu espectro de ação [...]”.

$\mathrm{Na}$ implementação do PMGIRS/Natal estão envolvidos atores públicos municipais responsáveis pela operacionalização de ações do plano e implementação de ações de educação ambiental. Fazem parte também as Cooperativas de Catadores do município de Natal, responsáveis pela coleta e separação dos resíduos recicláveis, e atores privados classificados como grandes geradores de resíduos pertencentes à categoria de supermercados varejistas, shopping centers e instituição de ensino superior. Como se pode constatar, o desenho da política implica a presença de atores muito distintos e com interesses muito diversos, demandando, para sua efetivação, uma forte articulação entre os mesmos. A pluralidade de atores e interesses traz, por si só, um grande potencial de conflito nas relações que serão estabelecidas.

Assim, uma das preocupações da pesquisa consistiu em saber dos atores o grau de conhecimento em relação aos princípios, objetivos, conceitos e instrumentos contidos na PNRS (2010), uma vez que ela estabelece instrumentos importantes, a exemplo do PMGIRS. Importa ressaltar que o conhecimento da legislação deve ser, desde já, relativizado, dado que não basta conhecer para agir. No entanto, o conhecimento da norma é fundamental para orientar a ação dos atores, evidenciar as competências dos atores no PNRS (2010), as mudanças estruturais propostas aos órgãos municipais advindas com o novo modelo de gestão de resíduos, o princípio da gestão compartilhada e o PMGIRS/Natal.

Para Martins e Murari (2013, p. 19), "a PNRS tem sua espinha dorsal na temática da sustentabilidade. Pressupõe a tomada de consciência sobre o papel ambiental, econômico, social e político que cada cidadão desempenha em sua comunidade [...]". Ao opinar a esse respeito, a entrevistada OPM2 (comunicação pessoal, 07 de março de 2017) afirmou:

Eu acho que é uma lei importante, que de certa forma, obriga o município a olhar para a questão ambiental. Um aspecto positivo que eu vejo foi a adaptação da estrutura da secretaria para atender essa questão do plano municipal. Mas, já em relação ao plano municipal, eu também não tenho muito conhecimento não.

Nota-se que a entrevistada, apesar de achar a lei importante, atuar no setor público e desenvolver atividades relacionadas à gestão dos resíduos sólidos, demonstra não ter conhecimento sobre a PNRS e seus instrumentos, como é o caso do PMGIRS. O desconhecimento da lei também emerge nas declarações de entrevistados do setor privado, como pode ser visto a seguir.

A entrevistada ESV (comunicação pessoal, 08 de março de 2017) diz conhecer a PNRS, mas, ao ser perguntada sobre os aspectos positivos e negativos, fala apenas das iniciativas da empresa em relação aos resíduos.

Sim, conheço a política. Aqui na empresa os clientes elogiam muito a iniciativa de ter essa estação de coleta seletiva. Inclusive nós somos arrodeados de condomínios, né? Então, os clientes fazem questão de separar o lixo reciclável e trazer pra colocar na estação. Esta estação é um projeto conjunto da Unilever com o grupo Extra, é ela quem paga esse serviço junto a Cooperativa Coopcicla. 
Na mesma linha, o entrevistado ESC (comunicação pessoal, 08 de março de 2017) expôs sua opinião: "Eu acho a PNRS muito vaga. E como o shopping tem uma política de adotar práticas que busquem a melhoria na questão ambiental, a gente está sempre pesquisando sobre questões de reuso”. Já o entrevistado ECT (comunicação pessoal, 07 de março de 2017) disse não conhecer a Política Nacional de Resíduos Sólidos: "Não, não conheço. Eu não tenho estudo pra saber dessas coisas".

Essa falta de conhecimento por parte de alguns atores em relação aos princípios, aos objetivos, aos conceitos e aos instrumentos contidos na PNRS (2010) cria enormes dificuldades para a efetivação dos planos de gestão, entre outros instrumentos relacionados à Lei. O desconhecimento da lei implica uma elaboração pouco efetiva no que se refere aos planos de gestão integrada de resíduos sólidos dos municípios e em relação ao plano de gerenciamento de resíduos sólidos destinado aos geradores de resíduos do serviço público de saneamento básico, resíduos industriais, resíduos de saúde, resíduos de mineração, para estabelecimentos comerciais que geram resíduos perigosos, grandes geradores e empresa de construção civil.

Ao ser questionada em relação ao modelo de gestão dos resíduos sólidos, a entrevistada OPM1 (comunicação pessoal, 07 de março de 2017) afirma que:

A resistência que eu vejo é em relação a realizar as metas do plano. [...] Questão de planejamento, sabe? O planejamento é uma coisa ainda deixada para depois, para terceiro plano. É aquela coisa imediatista do tipo "vamos fazendo, vamos fazendo" [...], conforme a demanda aparece. [...] Eu vejo o plano como de extrema importância.

A entrevistada EUB (comunicação pessoal, 10 de março de 2017), ao abordar a necessidade de mudança na gestão estratégica dos resíduos sólidos, destaca a importância do planejamento estratégico, mas também faz críticas quanto à postura dos órgãos governamentais, ao afirmar que: "Com um planejamento você tem que fazer toda uma identificação de uma realidade com um diagnóstico e em cima dele você vai traçar o que você quer. Economiza recursos”. A entrevistada reconhece que a política trouxe avanços em relação ao tratamento dos resíduos sólidos no município, "mas, avanços tímidos, muito tímidos em relação à postura da sociedade". Seu ponto de vista remete a Théret (2003, p. 228) quando afirma que se "as instituições determinam as condutas individuais, elas deveriam também se perguntar para onde conduz a orientação e quais são suas implicações". As instituições funcionam como um meio de coordenar as ações do indivíduo, regulando, por meio de normas e regras, o comportamento deste em relação a questões sociais, econômicas e ambientais. Nesse processo, o objetivo de uma política pode levar tempo para ser alcançado, haja vista que uma mudança de comportamento satisfatória demora para se concretizar.

Já os entrevistados ECT, ESV, ESC, OPM2, OPM3 e OPM4 (comunicação pessoal, 14 de março de 2017), por desconhecerem o conteúdo da PNRS, não opinaram. Vale ressaltar que os entrevistados OPM2, OPM3 e OPM4 (comunicação pessoal, 14 de março de 2017), apesar de atuarem em ações relacionadas à execução do PMGIRS, demonstram não ter conhecimento do plano, o que leva a um descompromisso com a implementação de suas ações.

Além da obrigatoriedade do plano de gestão para os resíduos sólidos, a Política Nacional de Resíduos Sólidos (PNRS, 2010) também define um conjunto de princípios para facilitar a sua efetivação. Um desses princípios consiste na responsabilidade compartilhada pelo ciclo de vida de produtos, conforme art. $6^{\circ}$, inciso XVII. Nessa perspectiva, efetuar ações que promovam a destinação correta de resíduos exige a participação do poder público, da comunidade e dos fornecedores.

O princípio da responsabilidade compartilhada exige dos elementos envolvidos articulação necessária para a execução da política, bem como ter por base o princípio da visão sistêmica. A responsabilidade compartilhada é vista como um aspecto positivo, principalmente em termos de conscientização do indivíduo, como é destacado pelo entrevistado ESB1 (comunicação pessoal, 15 de março de 2017), que afirma:

Eu acho que é uma política importante. Um aspecto positivo que eu vejo é a responsabilidade compartilhada, principalmente para gente que trabalha com Educação Ambiental. Essa coisa de dividir a responsabilidade com todos pela gestão dos resíduos, por exemplo, é fundamental. Como aspecto negativo, acho que ela é muito vaga o que dá margem a diversas interpretações. 
Apesar de a educação ambiental ser um fator importante na continuidade do processo da responsabilidade compartilhada, os demais entrevistados, ao serem abordados sobre responsabilidade compartilhada, direcionaram suas falas para a questão da coleta seletiva, que é também um elemento fundamental para a continuidade do processo do ciclo de vida de um produto. Infere-se, portanto, que a responsabilidade compartilhada não é uma prática cotidiana dos diversos atores envolvidos com a gestão dos resíduos sólidos e, assim sendo, deixa de ser um elemento capaz de criar consensos sobre os problemas envolvidos com a gestão e, na sua ausência, se estabelecem maiores dificuldades para a implementação da política.

Em relação à coleta seletiva, a PNRS (2010), o artigo $8^{\circ}$, inciso III, estabeleceu a coleta seletiva como um de seus instrumentos, reforçando a necessidade de sua valorização e difusão (Bechara, 2013). A coleta seletiva deve ser executada com base na ótica da responsabilidade compartilhada, isto é, deve acontecer a partir da atuação conjunta entre poder público, empresários e consumidores, pois a coleta é essencial para que se atinja o processo de disposição final ambientalmente adequado.

No município de Natal, a atividade da coleta seletiva se dá por meio de contrato realizado entre a prefeitura e as cooperativas de catadores para a execução do serviço. Existem duas Cooperativas, COOCAMAR e COOPCICLA, que juntas somam em torno de 130 cooperados e atendem 15 dos 36 bairros que compóem o município. Esse baixo número de cooperados não atende à demanda do município, o que coloca em risco a realização das ações do plano. Isso se deve ao fato de que muitos dos ex-catadores do lixão optaram por viver na informalidade, exercer a atividade de carroceiros, alegando que conseguem uma renda melhor do que um associado de cooperativa.

Para uma grande geradora de resíduos, em sua relação com as cooperativas de catadores, existem algumas dificuldades, tais como:

Eu trabalhei muito perto das cooperativas na capacitação. Há uma ingerência muito grande de algumas instituições. Por exemplo, a universidade, a gente ofereceu capacitação de graça aos catadores na parte de gestão, de segurança do trabalho, gestão financeira, organização para que eles agilizassem a questão da documentação das pessoas, de tudo. [...] Mas, por interferências outras, que não sei explicar quem acabou fazendo esse trabalho foi uma [organização não-governamental] ONG, que recebeu por isso, e a gente viu que os cursos não atendiam. [...] Assim a gente acaba não entendendo. Então, acaba tendo essa ingestão. Eles ficam muito dependentes da prefeitura também. Tem essa questão dos caminhões, das rotas e tudo mais. Então, eu acho que há uma interferência muito grande nisso (EIES, comunicação pessoal, 15 de março de 2017).

Os entrevistados OPM4, ESV e ESC (comunicação pessoal, 14 de março de 2017) não opinaram sobre os pontos positivos ou as dificuldades em relação às atividades das cooperativas, afirmando não ter conhecimento suficiente para formular uma opinião a respeito. A ausência de posicionamento desses entrevistados por falta de conhecimento sobre a atuação das cooperativas se justifica tendo em vista que o entrevistado OPM4 (comunicação pessoal, 14 de março de 2017) está há pouco tempo na função e não se envolveu ainda com atividades que exigissem, de modo direto, a participação das cooperativas. Quanto aos entrevistados ESV e ESC (comunicação pessoal, 08 de março de 2017), estes, por serem grandes geradores de resíduos, atendem a legislação específica quanto ao destino de seu resíduo orgânico e, dado o grande volume de material reciclável, realizam a venda de seus resíduos recicláveis diretamente às empresas de reciclagem, conforme $\$ 3$ da Lei n. 6.227/2011, não fazendo uso dos serviços de coleta seletiva oferecido pela prefeitura.

Constata-se que a relação entre os atores é tensionada com frequência, seja por desconhecimento, incapacidade de coleta, capacitação, fiscalização e envolvimento. Todos esses fatores criam entraves para a plena efetivação da implementação do plano e evidenciam que um dos problemas centrais é uma estrutura de governança com muitas fragilidades.

Importa ressaltar que, em relação aos grandes geradores de resíduos, o município de Natal possui legislação específica como uma das ações do PMGIRS/Natal (2012) para atuar junto aos condomínios verticais, auxiliando sua adaptação à lei municipal n. 6.227, de 25 de março de 2011, que estabelece que os condomínios, a partir de dez moradias, devem construir a casa do lixo e destinar seus resíduos recicláveis às cooperativas de catadores do município[2]. Apesar de ser uma exigência para o licenciamento de novos 
condomínios, a preocupação principal está em adequar os antigos condomínios às exigências da lei. Sobre a atuação junto aos condomínios, a entrevistada OPM2 (comunicação pessoal, 14 de março de 2017) afirma: "Existe uma defasagem na atividade da coleta seletiva e para o programa junto aos condomínios andar isso tem que ser resolvido, porque pela lei a gente tem que destinar o material pra eles".

Considerando a necessidade em relação à adequação dos condomínios à coleta seletiva, nota-se que o baixo número de catadores oferecidos pelas cooperativas é um obstáculo à oferta de serviço que atenda satisfatoriamente aos munícipes. No entanto, a prefeitura, atendendo às especificações contidas no PMGIRS/Natal, tem contrato firmado com as duas cooperativas até o ano de 2021, o que vem gerando discussões em relação a uma solução mais imediata para a questão.

Como órgão responsável pela fiscalização dos serviços de coleta seletiva oferecido pelas cooperativas de catadores, o OPM1 é responsável, também, pelo estabelecimento das rotas de coleta a serem realizadas nos bairros. O descumprimento das rotas estabelecidas por parte das cooperativas é uma das preocupações do OPM1, pois reflete diretamente na qualidade do serviço ofertado.

A atuação do OPM1 em relação às atividades de fiscalização e estabelecimento das rotas de coleta é vista pelo entrevistado ECT (comunicação pessoal, 14 de março de 2017) da seguinte forma: "Na cooperativa, ali tem muita briga. As coisas precisam melhorar. Quando mudar o presidente eu acredito que as coisas vão mudar. $\mathrm{Na}$ verdade, eu queria que a URBANA tomasse conta das cooperativas. Aí sim, as coisas iam melhorar".

O comentário feito pelo representante dos catadores demonstra a falta de entendimento existente entre as cooperativas, o que se reflete claramente no serviço ofertado pelos mesmos. Quanto à falta de unidade entre atores coletivos, Subirats (2009, pp. 51-52) afirma: "Um conjunto de indivíduos só constituirá um ator unitário sempre e quando, no que concerne a política pública, se apresente e atue com homogeneidade interna em relação aos valores e interesses que defende e aos objetivos que persegue". Neste sentido, fica difícil considerar como ator um agrupamento com divisões internas sobre o problema e as soluções a adotar.

Vale destacar que é notória a pouca habilidade dos catadores em relação à gestão das cooperativas, o que os torna muito dependentes de orientações do OPM1 na realização de suas atividades. A esse respeito, a entrevistada EIES (comunicação pessoal, 15 de março de 2017) comenta que:

Em relação à URBANA eu vejo alguns problemas. Por exemplo, uma falta de visão do futuro. Falta de planejamento. Eu já trabalhei com a URBANA e outras instituições, como o programa “Água Brasil” aqui em Natal, e a gente viu que em 2014 e 2015 era para ter 36 eco-pontos em Natal e até hoje só tem 3 eco-pontos funcionando direito. Então, que preocupação com investimento nessa área, tem o órgão que deveria estar pensando nisso. Outra coisa, a questão da capacitação dos catadores, eu acho que falta um pouco de visão, acho que fica muito no operacional, não sei.

Apresentando uma opinião bem similar, a entrevistada EIES (comunicação pessoal, 15 de março de 2017) afirma: "Na minha visão, enquanto a prefeitura não planejar, não se vai ter um resultado a contento pra se pensar em coleta seletiva no município". A entrevistada ESV (comunicação pessoal, 14 de março de 2017) aponta: "Eu entendo que, em termos de coleta seletiva, a URBANA não deve estar atendendo o que é esperado. Porque tem muitos clientes que trazem de carro os materiais que separam para entregar na estação de coleta seletiva daqui".

Nesse processo, o OPM1 exerce parte de suas atividades em parceria com outros órgãos municipais, que apontaram não ter problema ao exercer atividades junto com o órgão. Como afirma a entrevistada OPM2 (comunicação pessoal, 14 de março de 2017), "a gente trabalha em parceria com a URBANA e a gente trabalha muito bem”, o entrevistado OPM3 (comunicação pessoal, 14 de março de 2017) comenta: "Eu noto o pessoal da URBANA bem engajado e sempre que a gente quer fazer algum trabalho junto a gente tem facilidade". Por fim, a entrevistada OPM4 (comunicação pessoal, 14 de março de 2017) diz: "Não tenho problemas na parceria com a URBANA, principalmente em trabalhar com a Diretoria de Planejamento e Gestão Ambiental”. 
Os entrevistados ESV e ESC (comunicação pessoal, 08 de março de 2017), por utilizarem serviço específico de coleta de resíduos e não destinarem seus resíduos recicláveis às cooperativas, não emitiram opinião sobre o serviço de coleta seletiva.

A preocupação com a consciência do cidadão pode ser vista também no art. $6^{\circ}$ do Decreto n. 7.404/2010, que regulamenta a PNRS (2010) ao determinar:

Os consumidores são obrigados, sempre que estabelecido sistema de coleta seletiva pelo Plano Municipal de Gestão Integrada de Resíduos Sólidos (PMGIRS) ou quando instituídos sistemas de logística reversa na forma do Art. 15, a acondicionar adequadamente e de forma diferenciada os resíduos sólidos gerados e a disponibilizar adequadamente os resíduos sólidos reutilizáveis e recicláveis para coleta ou devolução (Decreto n. 7.404, 2010).

Como uma alternativa para se trabalhar o comportamento dos munícipes, surgem os programas de educação ambiental. Segundo a entrevistada OPM1, a educação ambiental é fundamental: "A educação é um processo. Não é fazer uma palestra, uma campanha que eu estou fazendo educação ambiental. Eu acho que eu estou utilizando de ações dentro de um processo, que como tudo tem que ser integrado, contínuo”. A falta de conscientização ambiental por parte do cidadão mostra um aspecto controverso entre o conteúdo das normas e ações estabelecidas por meio de programas de educação ambiental pelo órgão municipal e a forma de apropriação desse conteúdo por parte da sociedade. No entanto, existem questões sociais e de segurança pública que impedem a realização de programas de educação ambiental. Ao comentar sobre a importância da educação ambiental para a conscientização da comunidade, o entrevistado OPM3 (comunicação pessoal, 14 de março de 2017) comenta:

A nossa demanda por cursos de educação ambiental vem de áreas com pessoas esclarecidas, mas a gente fez um projeto para trabalhar com pessoas carentes. Escolhemos como modelo piloto a comunidade no Parque São Jorge, que é o antigo Maruim. Além de informações sobre cuidados com o meio ambiente pretendíamos levar cabeleireiro, ponto móvel pra retirada de carteira de identidade e dentista, mas a pessoa responsável pelo centro comunitário disse que lá não poderia ser utilizado no momento pois era ponto de venda de drogas, mas que ia tentar negociar, com a ajuda da igreja, para poder voltar a usar o salão.

Para os entrevistados ESV e ESC (comunicação pessoal, 08 de março de 2017), a falta de educação ambiental está na ausência de compromisso por parte do cidadão, que não procura realizar uma mudança de hábitos. A esse respeito, o entrevistado ECT (comunicação pessoal, 14 de março de 2017) não opinou.

A multiplicidade de atores envolvidos (supermercados, órgãos públicos municipais, shoppings, catadores, instituição de ensino superior), o modo como as ideias oriundas com a política caminha por meio da interação entre eles e a forma como a legislação relacionada à atividade desenvolvida por eles é executada explica muito sobre a implementação do PMGIRS.

Sobre a postura dos atores em relação a uma política pública, Subirats (2009, p. 52) afirma que:

“Todo indivíduo ou grupo social envolvido em um problema coletivo que origina a política pública se considera um ator potencial que poderia formar parte do 'espaço' da mencionada política. De fato, o comportamento mais ou menos ativo de um ator influenciará a maneira em que termina sendo concebida e posta em prática a intervenção pública em questão”.

O exame dessas interações e modus operandi dos atores permite compreender, por exemplo, o desconhecimento da PNRS (2010) por parte de grandes grupos empresariais, pois apesar de a PNRS (2010) instituir o princípio da responsabilidade compartilhada, a conduta dos mesmos em relação à gestão dos resíduos sólidos distancia-os, de certa forma, da interação com as ações de outros atores envolvidos no processo de gestão compartilhada dos resíduos.

Constata-se, pois, que a dinâmica de implementação da PMGIRS que implica mobilização de recursos, estabelecimento de articulações, realização de metas, programas e planos alcança os atores de forma distinta e mostrou que a multiplicidade de atores envolvidos na execução da gestão de resíduos sólidos e a interação entre eles geraram uma profusão de ideias e ações que resultaram em duas dinâmicas: Uma de impulsionar e outra de limitar a implementação das ações do PMGIRS/Natal (2012). 
A dinâmica de impulsionar decorre da realização de ações positivas relativas ao PMGIRS/Natal (2012), tais como ações de responsabilidade compartilhada que agilizam a execução das ações do PMGIRS, de educação ambiental que auxiliam na compreensão dos problemas da gestão dos resíduos, de coleta seletiva e ações pró-ambientais aplicadas por meio dos grandes geradores.

Por sua vez, a dinâmica de limitar opera pela não realização de atividades positivas relativas ao plano, em função do desconhecimento dos instrumentos legais e suas diretrizes, do baixo número de catadores e das ações falhas na coordenação dos atores envolvidos na execução de ações do PMGIRS.

Outros elementos que impulsionam e intermediam a interação entre os atores consistem em normas, decretos e regulamentações relacionados à gestão integrada dos resíduos sólidos. A multiplicidade de atores, assim como de suas atividades, resulta na utilização de diversos elementos legais, de modo a auxiliar na regulação da interação de atividades distintas. No entanto, a aplicação de diversas normas e decretos gera, muitas vezes, a aplicação de legislação específica, proporcionando uma fragmentação da legislação, o que influencia o modo de atuação dos atores em relação à execução das ações do PMGIRS/Natal (2012).

Essas dinâmicas que operam conjuntamente põem em realce a necessidade de criar mecanismos de governança que estreitem as interações e a construção de consensos entre os atores sobre os desafios a serem superados para a implementação do PMGRIS, que é de extrema complexidade.

\section{Conclusões}

Este estudo buscou analisar o papel dos diversos atores envolvidos no processo de implementação do PMGIRS e as transformações ocorridas na gestão de resíduos sólidos do município resultantes das articulações ocorridas durante a sua execução.

O PMGIRS/Natal (2012), como instrumento de uma política oriunda do governo federal, teve sua implementação a partir da interação entre atores públicos e privados e pode ser melhor compreendida a partir de uma perspectiva de modelo bottom-up de execução, reforçando a complexidade envolvida em sua implementação.

A análise do papel dos atores e dos elementos do contexto institucional em relação à gestão dos resíduos sólidos do município revelou um total desconhecimento da Política Nacional de Resíduos Sólidos e de outros dispositivos legais do município por parte de alguns atores tidos como grandes geradores. Nesse caso, a falta de conhecimento da lei é um dos aspectos que dificulta a integração entre os atores envolvidos na implementação, uma vez que a legislação define as competências distintas cabíveis aos múltiplos atores.

É importante ressaltar que os atores envolvidos na dinâmica de execução das ações do PMGIRS/Natal (2012) demonstraram estar atentos em relação às questões ambientais ao executarem ações pró-ambientais, seja ao atender as exigências legais, seja ao executar diretrizes provenientes da matriz das empresas que representam. No tocante ao princípio da responsabilidade compartilhada de resíduos, parte dos atores demostrou ser favorável à dinâmica do processo de compartilhamento de responsabilidades, haja vista que alguns deles obtêm retorno financeiro por meio da venda de material reciclável que, por sua vez, impulsiona e valoriza a indústria da reciclagem a partir do reaproveitamento de resíduo.

Considerando a interação entre os atores e, consequentemente, a execução de ações do PMGIRS/ Natal (2012), nota-se que na Região Nordeste ocorreu a redução de investimentos, bem como das ações que implicam na execução de um gerenciamento ambientalmente adequado dos resíduos sólidos, Os "recursos aplicados na coleta de resíduos sólidos urbanos e demais serviços de limpeza urbana na Região Nordeste apresentaram um decréscimo entre o ano de 2017 (R $\$ 2.163$ milhões por ano, significando $R$ $\$ 3,15$ pormês por habitante) e o ano de 2018 ( $\mathrm{R} \$ 2.139$ milhões por ano, significando $\mathrm{R} \$ 3,14$ por mês por habitante)" (Associação Brasileira de Empresas de Limpeza Pública e Resíduos Especiais [ABRELPE], 2019, p. 26). Essa redução de investimentos na coleta de resíduos sólidos dificulta as ações de gestão, tanto por parte 
do poder público, quanto por parte dos atores responsáveis, haja vista o grande volume de resíduos gerados pelo município.

O PMGIRS/Natal (2012) apresenta dificuldades em seu processo de implementação também em função da estrutura de governança que opera a execução do plano. Não há como orientar as ações para o alcance de um objetivo se não houver uma estrutura organizada que dê sustentação à cooperação e à coordenação das atividades. A estrutura estabelecida para implementação da política, em nível local, envolve diversos atores públicos e privados que devem atuar de forma conjunta para o alcance dos objetivos do plano. No entanto, por envolver um número variado de atores, é necessário compreender se suas ideias e percepções estão alinhadas com as ideias que regem a política com que estão envolvidos. $\mathrm{O}$ distanciamento dos atores que atuam na implementação do plano dos atores que formularam a política reforça o desconhecimento do conteúdo da PNRS e das ações que compõem o PMGIRS/Natal.

Para ampliar a compreensão sobre a implementação do PMGIRS/Natal (2012), sugere-se como estudo futuro a realização de pesquisa sobre a sua estrutura de governança, de modo a trazer uma melhor articulação e coordenação entre os atores, em função da complexidade que envolve a execução do plano. A falha na estrutura de governança da URBANA levou à ineficiência institucional-administrativa do órgão, ao operacionalizar a execução do PMGIRS/Natal (2012), em que o não cumprimento de normas e regras pelos atores envolvidos nas ações da gestão de resíduos sólidos, o monitoramento deficiente das ações da cooperativa de catadores e o desconhecimento, por parte dos atores, da PNRS e do PMGIRS/Natal (2012) gerou gargalos limitadores de esforços em torno da realização das açóes propostas, o que compromete a implementação do plano.

Concluindo, diante da confluência de duas dinâmicas, de impulsionar e de limitar as ações que envolvem a implementação do PMGIRS/Natal, faz-se necessário repensar mecanismos da estrutura de governança que ponham em destaque o conjunto de políticas propostas, em conformidade com o art. 19 da PNRS (2010), avaliando-as do ponto de vista de sua viabilidade, eficácia e efetividade para a gestão dos resíduos sólidos.

\section{REFERÊNCIAS}

Associação Brasileira de Empresas de Limpeza Pública e Resíduos Especiais [ABRELPE]. (2019). Panorama de resíduos sólidos no Brasil - 2018/2019. Recuperado de http://abrelpe.org.br/download-panorama-2018-2019.pdf.

Bechara, E. (Org.) (2013). Aspectos relevantes da politica nacional de resíduos sólidos. São Paulo: Atlas.

Decreto n. 7.404, de 23 de dezembro de 2010. (2010). Regulamenta a Lei no 12.305, de 2 de agosto de 2010, que institui a Política Nacional de Resíduos Sólidos, cria o Comitê Interministerial da Política Nacional de Resíduos Sólidos e o Comitê Orientador para a Implantação dos Sistemas de Logística Reversa, e dá outras providências. Recuperado de http://www.planalto.gov.br/ccivil_03/_ato2007-2010/2010/Decreto/D7404.htm

Lascoumes, P., Le Galès (2012). Sociologia da ação pública. Tradução e estudo introdutório George Sarmento. Maceió: Edufal.

Lei n. 12.305, de 2 de agosto de 2010. (2010). Institui a Política Nacional de Resíduos Sólidos; altera a Lei n. 9.605, de 12 de fevereiro de 1998; e dá outras providências. Brasília: Presidência da República.

Lei n. 6.227, de 25 de março de 2011. (2011). Dispõe sobre a obrigatoriedade de condomínios e edifícios residenciais com mais de dez unidades habitacionais a manterem em suas dependências recipientes destinados à separação de lixo orgânico e inorgânico, e dá outras providências. Diário Oficial do Município. Natal, RN: Prefeitura do Natal. Recuperado de https://www.legisweb.com.br/legislacao/?id=176121

Martins, J. X. F., Murari, G. G. (2013). Os princípios ambientais na política nacional dos resíduos sólidos: a questão principiológica. In E. Bechara (Org.), Aspectos relevantes da politica nacional de resíduos sólidos (pp. 01 - 30). São Paulo: Atlas.

Muller, P., Surel, Y. (2002). A análise das politicas públicas. Pelotas: Educat. 
Niederle, P. A., Grisa, C. Ideias e valores: a análise da ação pública a partir das interfaces entre a abordagem cognitiva e a economia das convençôes. Política \& Sociedade, 12(23), 97-136.

Oliveira, J. A. P. (2006). Desafios do planejamento em políticas públicas: diferentes visões e práticas. Revista de Administração Pública, 40(1), 273-288.

Pinto, M.F.N. Regulação e ação pública na educação infantil em Belo Horizonte. 2014. 261f. Tese (Doutorado em Educação) - Universidade Federal de Minas Gerais, Belo Horizonte, 2014.

Plano Estadual de Gestão Integrada de Resíduos Sólidos (2012). Elaborado pela Secretaria do Meio Ambiente e dos Recursos Hídricos. Natal, RN: SEMARH. Recuperado de http://www.semarh.rn.gov.br

Prefeitura do Natal. (2017). Limpeza Pública. Natal, RN: Urbana. Recuperado de https://natal.rn.gov.br/urbana.

Rodrigues. A. T. S. O modelo de gestão dos planos plurianuais: um estudo de caso. Brasília, UNB. 2010. Recuperado de http://repositorio.unb.br/bitstream/10482/3396/ 1/Dissert_Thalles\%20Rodrigues\%20de\%20Siqueira.pdf

Sabatier, P., Mazmanian, P. (1983). The implementation of public policy: a framework of analysis. Policy Studies Journal, 8(4), 538-560.

Sen, A. (1999). Desenvolvimento como liberdade. São Paulo: Companhia das Letras. Recuperado de https://www.fep .up.pt/docentes/joao/material/desenv_liberdade.pdf

Silveira, R. M. da C., Clementino, M. do L. M. (2017, maio). Novas regras, velhos entraves: o desafio da gestão dos resíduos sólidos nos municípios brasileiros. Anais do Encontro Nacional da Associação de Pós-Graduação e Pesquisa em Planejamento Urbano e Regional, São Paulo, SP, 17.

Simão, N. (2008). Desenvolvimento a caminho da sustentabilidade: dos primeiros tratados ao protocolo de Kyoto. In R. Pantalho Filho. Desenvolvimento sustentável (pp. 133-154). São Paulo: Berto.

Subirats, J. (2009). Análisis y gestión de políticas públicas. Barcelona: Ariel Ciência Política.

Théret, B. (2003). As instituições entre as estruturas e as ações. Lua Nova, 1(58), 25-55.

Van Meter, D. S., \& Van Horn, C. E. (1975). The policy implementation process: a conceptual framework. Administration \& Society, 6(4), 445-488.

\section{BY-NC-ND}

